\title{
JC virus detection in the cerebrospinal fluid of AIDS patients with progressive multifocal leucoencephalopathy and monitoring of the antiviral treatment by a PCR method
}

\author{
P. MATSIOTA-BERNARD, P. DE TRUCHIS*, F. GRAY $\uparrow$, M. FLAMENT-SAILLOUR*, E. VOYATZAKIS \\ and C. NAUCIEL
}

Laboratoire de Microbiologie, *Service des Maladies Infectieuses and +Laboratoire d'Anatomie Pathologique, Hôpital Raymond Poincaré, 92380 Garches, France

\begin{abstract}
Twenty-four cerebrospinal fluid (CSF) samples from 19 AIDS patients with neurological signs were analysed by the polymerase chain reaction (PCR) for the presence of JC virus $(\mathrm{JCV})$. Eleven of the 19 patients tested presented with progressive multifocal leucoencephalopathy (PML). Two specific JCV target sequences were used for the PCR analysis: a sequence specific for the $T$ antigen genes from both BK virus (BKV) and JCV (PCR1) and a sequence specific for the large T antigen gene from JCV (PCR2). The JCV genome was detected in 10 of 11 patients with PML by the PCR1 method and in all 11 patients by the PCR2 method. With samples from the eight patients without PML, one positive result was obtained with the PCR1 method and this sample and another gave positive results with PCR2. Multiple CSF samples were collected from three patients with PML at different times, including after intrathecal cytarabine treatment, and were tested by the PCR2 method for the presence of the JCV genome. The PCR result became negative for two of the three patients during the cytarabine treatment. However, the absence of a PCR signal was not associated with clinical improvement in these patients. The PCR method is useful for the detection of JCV in CSF samples and in the diagnosis of PML. However, the application of PCR for monitoring the effect of treatment remains to be established.
\end{abstract}

\section{Introduction}

The JC virus ( $\mathrm{JCV})$, a polyomavirus, is aetiologically linked with progressive multifocal leucoencephalopathy (PML), a severe subacute demyelinating disease of the central nervous system (CNS). PML is a rare complication of immunosuppressive treatment, but the general epidemiology of PML has run parallel to that of AIDS. The incidence of PML in patients with AIDS is estimated to range from 4 to $7 \%$ [1]. The classic triad of the disorder (dementia, hemiparesis, hemianopia) develops insidiously and death usually follows within 9 months. Brain biopsy remains the definitive diagnostic procedure. Besides characteristic histological features in such specimens, the viral antigen can be detected by immunofluorescence and the viral genome by in-situ hybridisation. Viral culture is often unsuc-

Received 25 Jan. 1996; revised version accepted 20 Aug. 1996.

Corresponding author: Dr P. Matsiota-Bernard. cessful. Among the non-invasive procedures, magnetic resonance imaging and computed tomography are useful for detecting the demyelinating lesions of PML [2]. Amplification of the viral genome by the polymerase chain reaction (PCR) has the advantage of detecting low concentrations of the viral genome. However, PCR studies have demonstrated the presence of JCV in brains of AIDS patients without clinically evident PML [3]. The aim of this study was to evaluate the diagnostic significance of a qualitative PCR method for the detection of JCV in the cerebrospinal fluid (CSF) of AIDS patients. CSF samples from patients with PML were also collected at different periods of time after intrathecal cytarabine treatment and tested by the PCR method for the presence of the JCV genome.

\section{Patients and methods}

Patients and samples

Twenty-four CSF samples from 19 AIDS patients with neurological symptoms were analysed. Eleven of the 
patients were considered to have PML on the basis of clinical symptoms, neuro-imaging and absence of any other infectious process. Neurological symptoms suggestive of PML were progressive motor weakness, ataxia, visual disturbance and dementia, and magnetic resonance imaging (MRI) features suggestive of PML were altered signals from subcortical lesions. The differential diagnosis between PML and HIV encephalitis was mainly established by MRI. The localisation of lesions in the subcortical white matter and their hypointensity in the T1-weighted images favoured the diagnosis of PML versus HIV encephalitis in these patients. Brain biopsy or necropsy were performed in seven of these 11 patients and the histopathological features were consistent with PML. CSF samples from three PML-positive patients were collected at different time periods, including after intrathecal cytarabine treatment.

CSF samples from eight AIDS patients with other neurological conditions were tested as PML-negative controls. Additional positive and negative JCV controls were used in every $\mathrm{PCR}$ reaction. CSF from a patient with necropsy features consistent with the presence of PML, virions visualised by electron microscopy and positive in-situ hybridisation (patient 'Nog', Table 1) was used as a positive control. CSF from an immunocompetent patient with pneumococcal meningitis was used as a negative control. The CSF samples were stored at $-20^{\circ} \mathrm{C}$ until tested.

\section{DNA extraction}

DNA was extracted from CSF by two methods. (1) CSF $(200 \mu \mathrm{l})$ was boiled for $10 \mathrm{~min}$ and frozen for another $10 \mathrm{~min}$. The boiling-freezing process was repeated three times. (2) CSF $(200 \mu \mathrm{l})$ was mixed with $400 \mu \mathrm{l}$ of a DNA extraction reagent (Perkin Elmer, NJ, USA)

Table 1. Diagnosis and PCR findings in AIDS patients with neurological signs

\begin{tabular}{llcc}
\hline Patients & Diagnosis & PCR1 & PCR2 \\
\hline Lel & PML & + & + \\
Che & PML & + & + \\
Dup & PML & + & + \\
Fer & PML & + & + \\
Moo & PML & + & + \\
Aka & PML & + & + \\
Bri & PML & - & + \\
Mas & PML & + & + \\
Nog & PML & + & + \\
Aro & PML & + & + \\
Cla & PML & + & + \\
Sam & C Toxo & + & + \\
XFa & C Toxo & - & - \\
Ben & C Toxo & - & - \\
Dup & HIV-enceph & - & - \\
Lop & VZV-mening & - & + \\
Men & HIV-enceph & - & - \\
Avi & HIV-enceph & - & - \\
Nob & C Lymphoma & - & - \\
\hline
\end{tabular}

PML, progressive multifocal encephalopathy; $C$ Toxo, cerebral toxoplasmosis; HIV-enceph, HIV encephalitis; C Lymphoma, cerebral lymphoma; VZV-mening, VZV meningitis. consisting of Chelex 100 (an anion exchange resin) $20 \% \mathrm{w} / \mathrm{v}$, suspended in $10 \mathrm{mM}$ Tris- $\mathrm{HCl}, \mathrm{pH} 8.0$, $1.0 \mathrm{~mm}$ EDTA, sodium azide $0.1 \%$. The mixture was boiled for $20 \mathrm{~min}$ and centrifuged at $10000 \mathrm{~g}$ for $20 \mathrm{~min}$ at $4^{\circ} \mathrm{C}$. The supernate was precipitated with ethanol $(2.5$ volumes $)$ in the presence of $5 \mathrm{M} \mathrm{NaCl}$ (0.04 volumes). After centrifugation at $10000 \mathrm{~g}$ for $20 \mathrm{~min}$ at $4^{\circ} \mathrm{C}$ and washing by centrifugation with ethanol $70 \%$ (twice), $50 \mu 1$ of Tris-EDTA $0.1 \%, \mathrm{pH}$ 7.5 , were added to the pellet.

\section{PCR method}

Two different couples of primers were used for PCR analysis of the DNA from the CSF. The set of primers PEP-1 and PEP-2 described by Arthur et al. (5'AGTCTTTAGGGTCTTCTACC-3', 5'-GGTGCCAACCTATGGAACAG-3') amplify the T-antigen genes (175 bp) from both BK virus (BKV) and JCV [4] (PCR 1). The set of primers JC3 and JC4 described by Henson et al. (5'-CAGGCTGATGAGCAAC-3', 5' TGCAAAGAACTCCACCCTG-3') amplify the large T-antigen gene (105 bp) from JVC [5] (PCR2). The PCR mixtures $(50 \mu \mathrm{l})$ used contained $10 \mu \mathrm{l}$ of the extracted DNA, deoxynucleotide triphosphates at a concentration of $200 \mu \mathrm{M}$ each, $10 \mu \mathrm{M}$ of primers, $1 \times$ reaction buffer $(50 \mathrm{mM}$ Tris- $\mathrm{HCl}, \mathrm{pH} \quad 8.5,17 \mathrm{mM}$ $\left(\mathrm{NH}_{4}\right)_{2} \mathrm{SO}_{4}, 2 \mathrm{mM} \mathrm{MgCl} 2,6.7 \mathrm{mM}$ EDTA, $10 \mathrm{mM} \beta$ mercaptoethanol, bovine serum albumin $0.1 \mathrm{mg} / \mathrm{ml}$ ), gelatin $0.01 \%$ and DNA Taq polymerase (Cetus, Perkin-Elmer, Norwalk, CT, USA) $0.5 \mathrm{U}$. This was overlaid with $100 \mu \mathrm{l}$ of mineral oil. The target DNA was amplified with 40 thermal cycles $\left(92^{\circ} \mathrm{C}\right.$ for $1 \mathrm{~min}$, $55^{\circ} \mathrm{C}$ for $1 \mathrm{~min}, 72^{\circ} \mathrm{C}$ for $2 \mathrm{~min}$, with a final elongation step of $72^{\circ} \mathrm{C}$ for $10 \mathrm{~min}$ ) in a Hybaid thermocycler. PCR products $(15 \mu \mathrm{l})$ were electrophoresed in an agarose $1.5 \%$ gel and visualised by exposure to UV light after staining with ethidium bromide.

\section{Results and discussion}

With the PEP-1/PEP-2 primers (PCR1), the JCV genome was detected in CSF from 10 of 11 patients with PML. CSF from one of eight patients without PML was positive for JCV by the PCR I method (Table 1). Therefore, the positive predictive value of PCR 1 was $91 \%$ and the negative predictive value was $87 \%$.

With the JC3/JC4 primers (PCR2), CSF from all 11 patients with PML gave a positive PCR signal and of the eight AIDS patients without PML, CSF from two patients gave a positive amplification band of the appropriate size (Table 1). Therefore, PCR2 had a positive predictive value of $85 \%$ and a negative predictive value of $100 \%$.

All results were reproduced twice and did not depend on the DNA extraction method used. However, CSF from the PML-negative patient 'Sam' gave positive 
results for the presence of the JCV genome by both PCR1 and PCR2 methods. In contrast, CSF from the patient 'Lop' gave a positive result for the presence of the JCV genome by the PCR2 method only and when his CSF was tested again after a period of 6 months, it gave negative results by both PCR methods. The positive PCR result for patient 'Lop' was likely to be a false positive result, while the reasons for the PCR positive result for patient 'Sam' are not clear.

CSF samples from three patients with PML were tested at different time intervals (Table 2), including after cytarabine treatment by the PCR2 method. The patients received intravenous cytarabine $(2 \mathrm{mg} / \mathrm{kg}$ daily for 5 days, repeated monthly); intrathecal cytarabine (50 mg) was given once a month. The PCR signal became negative for two of the three patients during the cytarabine treatment. The PCR signal from one patient did not change during cytarabine treatment, but CSF samples were tested only once after one course of treatment, because the patient died (Table 2). However, the PCR method was not a quantitative one, as no internal standards were used, so results must be interpreted with caution.

These results, in agreement with those obtained by others, suggest that PCR is a method that may prove useful in the diagnosis of PML. However, the two different pairs of primers used did not give divergent results, as reported by others $[6,7]$. Both pairs gave satisfactory results. It is noteworthy that the PCR signal was revealed by simple ethidium bromide staining. This may be due to the relatively large CSF volume $(200 \mu \mathrm{l})$ used. Results obtained with CSF volumes larger than $100 \mu \mathrm{l}$ correlated with the results from brain biopsy [6], but when smaller CSF volumes were used, this was not the case [5].

It has been suggested that the method of extracting DNA from the CSF may influence the outcome [6], although the two different extraction methods used in this study did not affect the results.

Digestion of the amplicons with restricted endonucleases and hybridisation with specific probes [6] were performed by others to verify the specificity of the JCV PCR. Another interesting approach for increasing confidence in the specificity of the PCR is the use of

Table 2. PCR results for JCV detection in the CSF of three patients with PML, before (A) and after (B) cytarabine treatment

\begin{tabular}{lcc}
\hline Patient & Date & PCR2 results \\
\hline Aro & $10.6 .91(\mathrm{~A})$ & + \\
Aro & $3.11 .91(\mathrm{~B})$ & \pm \\
Aro & $17.1 .92(\mathrm{~B})$ & - \\
Mas & $7.11 .90(\mathrm{~A})$ & + \\
Mas & $23.4 .91(\mathrm{~B})$ & - \\
Nog & $27.6 .90(\mathrm{~A})$ & + \\
Nog & $4.7 .90(\mathrm{~B})$ & + \\
\hline
\end{tabular}

nested primers or the sequencing of the amplicons, or both. In this study, the identification of the amplified products after PCR was performed by size determination in agarose gel and to improve the specificity of the PCR method, two sets of primers with different sequence targets were used comparatively. Corresponding PCR-positive results obtained with primers specific for $\mathrm{BKV} / \mathrm{JCV}$ and primers specific for only JCV suggest that the amplicons were both of the JCV genome.

A question that must be answered is whether the PCR method detects low amounts of the viral genome and subclinical infection. Several PCR studies have shown subclinical JCV infection in the CNS and circulating B lymphocytes of HIV-infected individuals [8]. The results of the present study correlated well with the presence of clinical disease. However, CSF from one AIDS patients with cerebral toxoplasmosis ('Sam' Table 1) gave positive PCR signals with both PCR1 and PCR2 methods, whereas at necropsy no histopathological features consistent with PML were found. An increase in the CSF cell numbers secondary to toxoplasmic encephalitis could account for the PCR positivity. The detection of a subclinical infection in the CSF of this patient cannot be excluded and the necessity for a quantitative PCR should be examined.

Finally, several nucleoside analogues have been used in the treatment of PML. Therapeutic trials with cytosine arabinoside suggest that the drug is effective [9]. However, less convincing results have been reported [10]. The preliminary results presented here suggest that when PCR was used for virological monitoring during cytosine arabinoside treatment, the PCR signal of the JCV genome became negative in two patients out of three. However, the negative PCR signal was not associated with clinical improvement. Furthermore, others have reported that the PCR method showed a stable or increased JCV-DNA burden in CSF during cytosine arabinoside treatment [11].

In conclusion, the PCR method can be used for the detection of JCV in the CSF and for the diagnosis of PML. The value of PCR for monitoring treatment effects remains to be established.

\section{References}

1. Berger JR, Kaszovitz B, Post MJD, Dickinson G. Progressive multifocal leukoencephalopathy associated with human immunodeficiency virus infection. A review of the literature with a report of sixteen cases. Ann Intern Med 1987; 107: 78-87.

2. Mark AS, Atlas SW. Progressive multifocal leukoencephalopathy in patients with AIDS: appearance on MR images. Radiology 1989; 173: 517-520.

3. Quinlivan EB, Norris M, Bouldin TW et al. Subclinical central nervous system infection with JC virus in patients with AIDS. $J$ Infect Dis 1992; 166: 80-85.

4. Arthur RR, Dagostin S, Shah KV. Detection of BK virus and JC virus in urine and brain tissue by the polymerase chain reaction. J Clin Microbiol 1989; 27: 1174-1179. 
5. Henson $J$, Rosenblum $M$, Armstrong D, Furneaux $H$ Amplification of JC virus DNA from brain and cerebrospinal fluid of patients with progressive multifocal leukoencephalopathy. Neurology 1991; 41: 1967-1971.

6. Moret $\mathrm{H}$, Guichard M, Matheron S et al. Virological diagnosis of progressive multifocal leucoencephalopathy: detection of JC virus DNA in cerebrospinal fluid and brain tissue of AIDS patients. J Clin Microbiol 1993; 31: 3310-3313.

7. Telenti A, Aksamit AJ, Proper J, Smith TF. Detection of JC virus DNA by polymerase chain reaction in patients with progressive multifocal leukoencephalopathy. J Infect Dis 1990; 162: $858-861$.

8. Tornatore C, Berger JR, Houff SA et al. Detection of JC virus
DNA in peripheral lymphocytes from patients with and without progressive multifocal leucoencephalopathy. Ann Neurol 1992; 31: $454-462$

9. Portegies P, Algra PR, Hollak CEM et al. Response to cytarabine in progressive multifocal leucoencephalopathy in AIDS. Lancet 1991; 337: 680-681.

10. De Truchis P, Flament-Saillour M, Urtizberea J-A, Hassine D, Clair B. Inefficacy of cytarabine in progressive multifocal leucoencephalopathy in AIDS. Lancet 1993; 342: 622-623.

11. Antinori A, De Luca A, Ammasari A et al. Failure of cytarabine and increased JC virus-DNA burden in the cerebrospinal fluid of patients with AIDS-related progressive multifocal leucoencephalopathy. AIDS 1994; 8: 1022-1024. 